\title{
Prevalence of low back pain and its effect on health-related quality of life in 409 scholar adolescents from the Veneto region
}

\author{
P. Galozzi', I. Maghini' ${ }^{2}$ L. Bakdounes ${ }^{3}$, E. Ferlito², V. Lazzari², M. Ermani ${ }^{4}$, \\ M. Chia ${ }^{5}$, D. Gatti ${ }^{6}$, S. Masiero ${ }^{2}$, L. Punzi \\ ${ }^{1}$ Rheumatology Unit, Department of Medicine DIMED, University of Padova, Padova; ${ }^{2}$ Rehabilitation Unit, \\ Department of Neuroscience, University of Padova, Padova; ' ${ }^{2}$ epartment of Physical Medicine \\ and Rehabilitation, Neurorehabilitation Unit "Villa Margherita", Vicenza; ${ }^{4}$ Department of Neurosciences, \\ University of Padova, Padova; ${ }^{5}$ Health and Motion Venice Association (HEMOVE), Venice; ${ }^{6}$ Rheumatology \\ Unit, Department of Medicine, Policlinico G.B. Rossi, Verona; ${ }^{7}$ Centre for Gout and Metabolic Bone \\ and Joint Diseases, Rheumatology, SS Giovanni and Paolo, Venice
}

\section{SUMMARY}

Low back pain (LBP) is a common condition with profound effects on well-being. We aimed to define the prevalence and the characteristics of LBP and to investigate its impact on the quality of life (QoL) of 409 students (265 females and 144 males), all high-school adolescents from the Veneto region. LBP was measured with a structured, self-report questionnaire, while the SF-36 questionnaire was used to measure physical and mental QoL.

253 students $(61.3 \%)$ reported one or more episodes of LBP, with female predominance. Adolescents with LBP treated with drugs and rehabilitation cares have significantly poor belief in pain resolution $(\mathrm{p}=0.005)$, but more belief in a prevention program $(\mathrm{p}=0.006)$ than the others. After adjustment for sex, a significant association between the SF-36 dimension of vitality and the presence of LBP in males was observed. All SF-36 domains except mental health were significantly higher in females with LBP.

Our study confirmed that LBP is frequent in Italian scholar adolescents and has an impact on QoL. Strategies for reducing the effects of LBP on QoL should be an important purpose for clinicians and health policy makers.

Key words: Low back pain; adolescents; quality of life.

Reumatismo, 2019; 71 (3): 132-140

\section{INTRODUCTION}

T ow back pain (LBP) is defined as pain and discomfort localized in the lumbosacral region of the back (1). It is a common condition in the industrialized countries and a relevant issue for national health services, considering that LBP is one of the most expensive health care disorders, registering increasing costs in recent years (2, 3 ). Recent studies show that LBP in adolescents is becoming as common as in adults; in particular, its prevalence is low in children (1-6\%) but strongly increases in adolescent age (up to $51 \%$ ) to approach that of adults $(4,5)$. According epidemiological data over the last two decades, most of the LBP episodes experienced by adolescents have non-specific origin, as observed in adults. Thus, LBP diagnosis remains one of exclusion (6).

Considering the high prevalence of LBP in adolescents, it is essential to study the relations between LBP and health care utilization (health providers consultations, diagnostic tests, drugs use and other treatments).

LBP is also a sensory and emotional experience that has intense effects on well-being and is often the cause of significant physical and psychological disability; hence the importance of considering it from a biopsychosocial perspective $(7,8)$. Since the complaints are subjective, the description and the quantification of this multi-dimensional experience are challenging.

Previous studies have demonstrated the strong impact of LBP on children's and ado- 
lescent's quality of life (QoL) (9). In up to $94 \%$ of this age group, LBP leads to a certain degree of disability and interferes with daily activity. Quality of life is the perceived quality of an individual's daily life. RothIsigkeit and colleagues reported that LBP limited daily activities in over 10 to $40 \%$ of adolescents (10). Short Form-36 Health Survey (SF-36), a 36-item generic measure of health status, is a valid self-reported survey of patient health. Until now, few studies have specifically used standardized and validated instruments to investigate potential effects of LBP on QoL (11).

The first aim of the present study is to observe and describe the presence of LBP in a sample of adolescent Italian population from the Veneto Region. Subsequently, the impact of LBP on social functioning, lifestyle and QoL was investigated.

\section{MATERIALS AND METHODS}

\section{Study population}

This cross-sectional study evaluated students from the $3^{\text {rd }}$ to the $4^{\text {th }}$ year of high school, 14-17 years of age, attending three different secondary schools located in Venice, Verona and Padua (Italy). Six different curricula were selected: liceo classico (classical studies), liceo scientifico (scientific studies), liceo artistico (fine arts studies), liceo musicale (music and choir studies), liceo delle scienze umane (liberal arts studies) and the liceo delle scienze applicate (applied sciences).

Data collection was carried out between October 2015 and November 2016, in agreement with the alternanza scuola-lavoro project endorsed by the Italian Ministry of Education, University and Research (MIUR) and approved by University Hospital of Padova. Written informed consent was obtained before taking part in the alternanza scuola-lavoro project, as stated by Law Decree 77/2005 and Law 107/2015, art. 1, paragraph 33 et seq.

\section{The questionnaires}

The study was based on a structured, selfreport non-validated questionnaire specially designed for this survey to collect epidemiological data, information on the presence and characteristics of LBP and to quantify its impact on health status and health-related quality of life. The SF-36, a 36-item questionnaire that measures eight multi-item dimensions of health was also administered. The questionnaires were anonymous and based on multiple-choice questions. Two members of our study team (MC and LB) presented and explained the two questionnaires to the students from each class during school hours. Each individual item was illustrated and the students were shown how to fill it in.

The epidemiological questionnaire was divided into four sections. The first part summarized personal details (date of birth, gender, residence, school attended and year, date of menarche, other comorbidities, physical activity, instrument played, smoking) and anthropometric factors (height, weight). The second section included questions on the occurrence of back pain nowadays and in the past, on the medical attention sought (primary care practitioner/ pediatrician, or specialist orthopedist, physiatrist, physiotherapist), on the referral for imaging studies (radiographs, magnetic resonance imaging, other), and pain localization (cervical, dorsal, lumbar and/ or sacral pain). Students were also asked in section three about prescribed forms of pain treatment (such as medication and physiotherapy), the types and the dosage of prescribed drugs (NSAIDs, analgesics, corticosteroids, muscle relaxants, natural products). In the last section, questions were asked about the consequences of the back pain on social functioning (absences from school and hindrance in daily physical activities).

The Italian version of the SF-36 questionnaire, the reliability and validity of which has been confirmed, was chosen to assess health-related quality of life (12). SF-36 is a generic tool that measures two major health concepts: physical and mental health, with 36 items generating eight multi-item scales: physical functioning (PF), physical role limitation (RP), bodily pain (BP), general health $(\mathrm{GH})$, vitality (VT), social functioning (SF), emotional role 
limitation (RE), and mental health (MH). For each patient, scores were summed up and then the raw scores were linearly transformed into 0-100 scales, with 0 and 100 assigned to the lowest and the highest possible values, respectively. The higher the individual's score, the better their quality of life.

Unfortunately, not all of the participants filled out the two questionnaires completely, leaving some questions blank.

\section{Statistical analysis}

The descriptive values were expressed by mean and standard deviations (SD). For normally distributed variables, the Student t test was used, while the Pearson's Chi Square test was applied to categorical vari-

Table I - Sociodemographic, lifestyle, anthropometric, and back pain characteristics of scholar adolescents from three different high schools in Veneto region, Italy.

\begin{tabular}{|l|c|}
\hline & $\begin{array}{c}\text { Baseline respondents } \\
(\mathrm{n}=409)\end{array}$ \\
\hline Age (mean, SD), year & $16.2 \pm 1.06$ \\
\hline Sex (males/females) & $144 / 265$ \\
\hline BMI (mean, SD), kg/m & $20.40 \pm 2.65$ \\
\hline Smoking - yes, $\mathrm{n}(\%)$ & $65(16)$ \\
\hline Playing an instrument - yes, $\mathrm{n}(\%)$ & $123(30)$ \\
\hline Practicing extra-school physical activity - yes, $\mathrm{n}(\%)$ & $246(60.1)$ \\
\hline School type: & \\
\hline Liceo classico/classical studies, $\mathrm{n}(\%)$ & $92(22.5)$ \\
\hline Liceo scientifico/scientific studies, $\mathrm{n}(\%)$ & $55(13.4)$ \\
\hline Liceo artistico/fine arts studies, $\mathrm{n}(\%)$ & $20(4.9)$ \\
\hline Liceo musicale/music and choir studies, $\mathrm{n}(\%)$ & $52(12.7)$ \\
\hline Liceo delle scienze umane/liberal arts studies, $\mathrm{n}(\%)$ & $143(35)$ \\
\hline Liceo delle scienze applicate/applied sciences, $\mathrm{n}(\%)$ & $47(11.5)$ \\
\hline Low Back Pain, $\mathrm{n}$ (males/females) & $127(50.1)$ \\
\hline Nowadays and in the past, $\mathrm{n}$ (\%) & $123(48.6)$ \\
\hline Nowadays only, $\mathrm{n}$ (\%) & $114(45)$ \\
\hline In the past only, $\mathrm{n}$ (\%) & $58(23)$ \\
\hline Sought professional advice - yes, $\mathrm{n}(\%)$ & $102(25.2)$ \\
\hline Referred for instrumental analyses - yes, $\mathrm{n}(\%)$ & $37(9.1)$ \\
\hline Taken medication - yes, $\mathrm{n}(\%)$ & $109(26.9)$ \\
\hline Rehabilitation treatments - yes, $\mathrm{n}(\%)$ & \\
\hline
\end{tabular}

BMI, body mass index. ables. The analysis of the results was stratified by gender, kind of course, age, physical activities, smoking and instrument played. Statistical significance was set at $\mathrm{p}<0.05$. Statistical processing was performed using the SPSS software (version 25, SPSS Inc., Chicago, USA).

\section{RESULTS}

A total of 415 students from the $3^{\text {rd }}$ to the $4^{\text {th }}$ year of high school were enrolled. Of the eligible students, 6 were excluded from the analyses due to missing data in the epidemiological questionnaire and/or in the SF-36 questionnaire, totalizing 409 adolescents in the analyses. The sociodemographic, lifestyle, and LBP characteristics of adolescents included in the study are described in Table I.

A total of 253 students $(61.3 \%)$ reported one or more episodes of LBP, with female predominance (152 students; 60.1\%). Multivariate linear regression stratified by sex showed a significant inverse association between males and the possible development of episodes of LBP (Table II). Multivariate analysis showed also a significant association between LBP and different types of school. The results revealed both an inverse association between LBP and the attendance of liceo classico (classical studies), and a strong association between the development of LBP and attendance at either liceo delle scienze applicate (applied sciences) or liceo artistico (fine arts studies) (Table II).

No correlations were observed between episodes of LBP and smoking or playing an instrument or practicing extra-school physical activity. However, the amount of time spent playing sports is associated with the presence of LBP ( $p=0.03$ ) (Figure 1). The percentages of the students reporting an aspect of care-seeking impact are reported in table 1 . There were differences about seeking professional advice $(\mathrm{p}=0.001)$, taking drugs $(\mathrm{p}<0.001)$ and undergoing rehabilitation treatments $(p<0.001)$ between those who experience LBP. Adolescents with LBP treated with both drugs and rehabilitation treatments have significantly 
Table II - Multivariate and univariate analysis of the prevalence of low back pain, according to gender, type of school and extra-school physical activity.

\begin{tabular}{|l|c|c|c|c|}
\hline & \multicolumn{2}{|c|}{$\begin{array}{c}\text { Univariate analysis } \\
\text { (Chi square) }\end{array}$} & \multicolumn{2}{c|}{$\begin{array}{c}\text { Multivariate analysis } \\
\text { (logistic regression) }\end{array}$} \\
\hline & $\begin{array}{c}\text { no LBP } \\
\text { (p value) }\end{array}$ & $\begin{array}{c}\text { LBP } \\
\text { (p value) }\end{array}$ & $\begin{array}{c}\text { no LBP Wald test } \\
\text { (p value) }\end{array}$ & $\begin{array}{c}\text { LBP Wald test } \\
\text { (p value) }\end{array}$ \\
\hline Gender & 0.046 & 0.014 & $8.115(0.004)$ & $9.922(0.002)$ \\
\hline Type of school & 0.002 & 0.056 & - & - \\
\hline Liceo classico/classical studies & 0.0004 & 0.0052 & $7.705(0.006)$ & $5.681(0.017)$ \\
\hline Liceo scientifico/scientific studies & 0.12 & 0.77 & - & - \\
\hline Liceo artistico/fine arts studies & 0.028 & 0.98 & $4.450(0.035)$ & - \\
\hline Liceo musicale/music and choir studies & 0.98 & 0.96 & - & - \\
\hline Liceo delle scienze umane/liberal arts studies & 0.87 & 0.16 & - & - \\
\hline Liceo delle scienze applicate/applied sciences & 0.064 & 0.05 & $4.970(0.026)$ & $7.999(0.005)$ \\
\hline Extra-school physical activity & 0.78 & 0.68 & - & - \\
\hline
\end{tabular}

Statistical significant $p$ value in italics.

poorer belief in pain resolution $(\mathrm{p}=0.005)$, but more belief in prevention programs $(\mathrm{p}=0.006)$ than the others.

Table III presents the means and standard deviation for all the SF-36 scores separately by the presence of LBP and gender. In all SF-36 domains, significant differences are observed between students with or without episodes of LBP and between males and females. Significant associations between specific SF-36 scores and the presence of LBP are also observed after adjustment for sex and reported in Table IV. Males with LBP display significantly higher VT score than males without episodes of LBP. All SF-36 domains except for $\mathrm{MH}$ are significantly higher in females with LBP than others.

\section{DISCUSSION}

During the past decades, LBP has been diversely studied in adolescents and different conclusions have been drawn in relation to the particular study design, sample size, geographical area and other factors.

Depending on the definition of pain, the recall period and the survey sample age, the reported prevalence of LBP in adolescents varies between studies. Asking directly about LBP at the moment of investigation and/or in the past, without defining a specific period of time, helped us to obtain precise and simple data.

Our study findings confirm the high frequency of LBP in late adolescence, indicating a significant future health risk considering the connection between LBP in adolescence and chronic LBP in adulthood $(13,14)$.

The study was conducted in 3 high schools located in the North East of Italy and six different curricula were analyzed; each

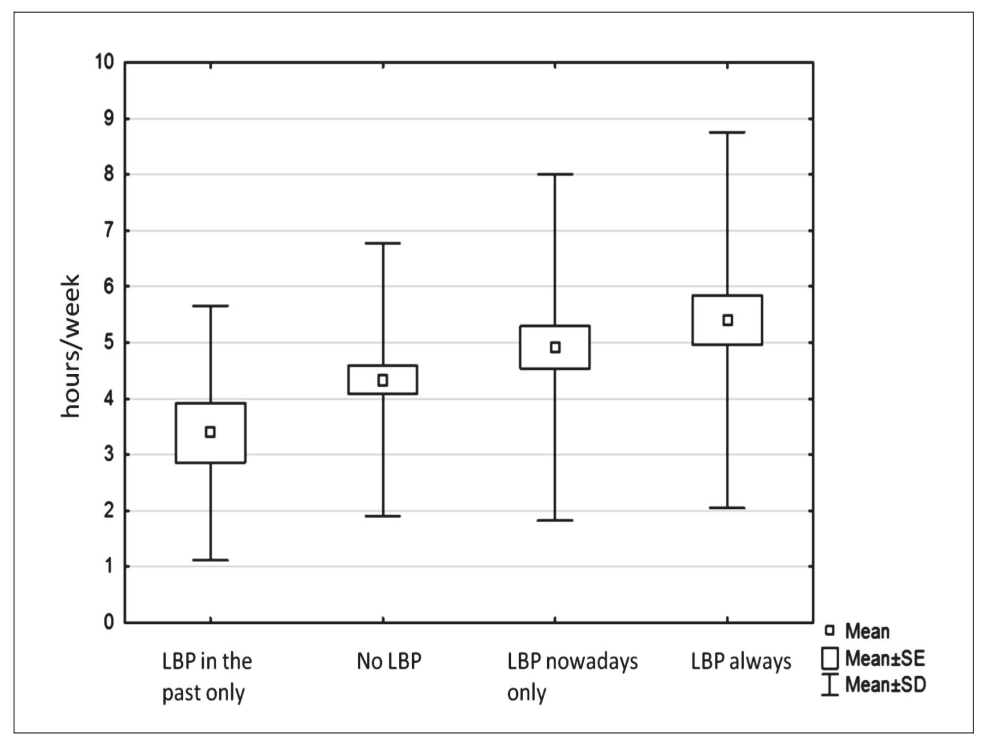

Figure 1 - Prevalence of low back pain (LBP) related to hours of sports per week. 

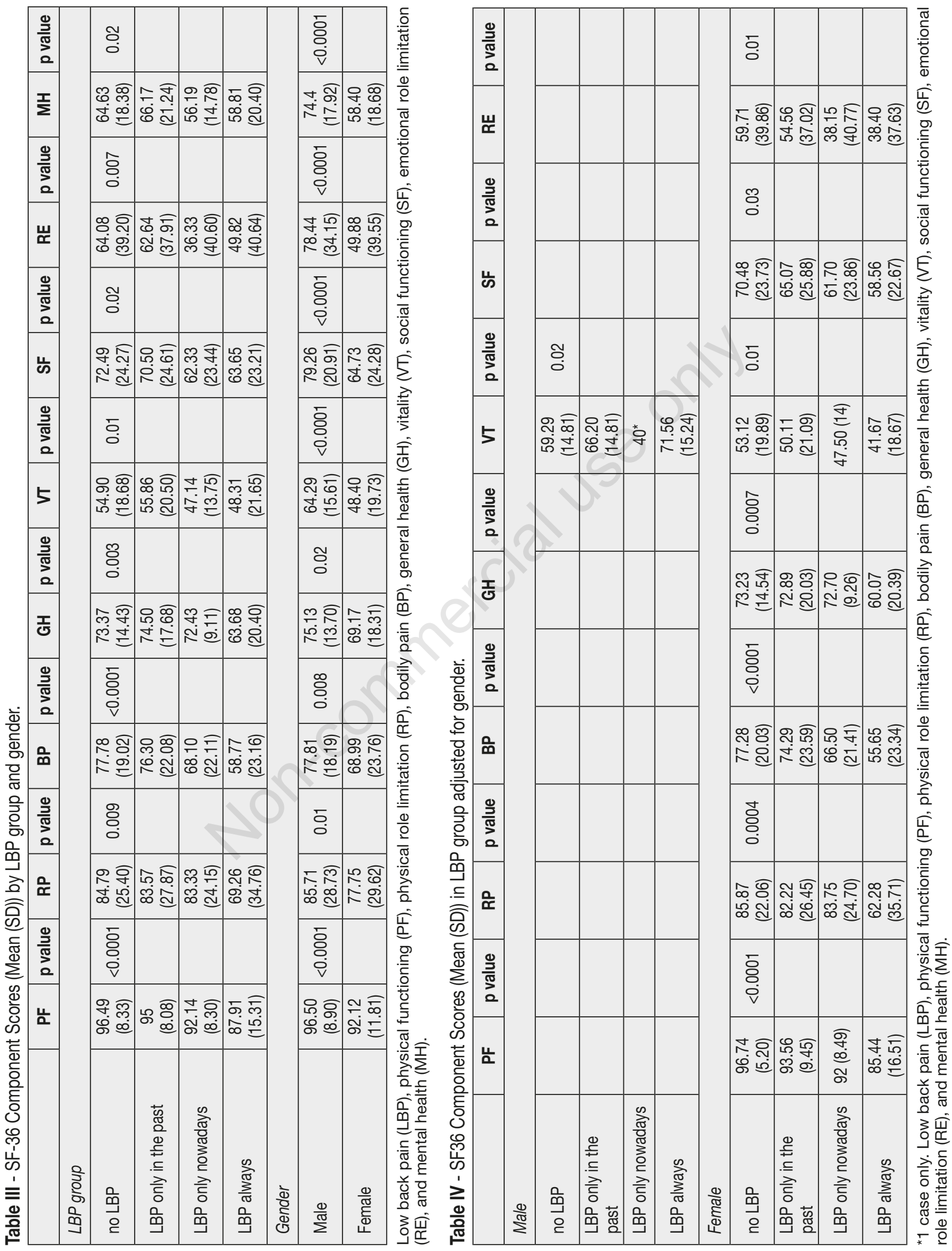
type of course has a different organization and teaches certain specific subjects.

The students selected were invited to complete, during class time and under the supervision of two members of our study team, a self-reported questionnaire, specially designed for this study. To analyze the impact of LBP on their quality of life, students were also asked to fill in a commonly used patient-reported survey of patient health. Considering the high mean age of the students of our study $(16.2 \pm 1.06$ years), we preferred not to use a HRQoL instrument designed to assess children's and adolescents' subjective health and well-being, but to choose the SF-36 questionnaire: a 36-item, patient-reported survey, validated in the Italian language, that measures eight dimensions of health and which is commonly used for adults too.

Stratifying the schools by type of curriculum, the results show that the adolescents attending the liceo artistico (fine art studies) or the liceo delle scienze applicate (applied sciences) had a higher probability of incurring at least one episode of LBP, meaning that the school environment can be one of the factors that contribute to the development of LBP. Inadequate postures combined with high stress and specific workloads for both types of high schools may explain the differences observed (15). In fact, in both schools, several hours per day are spent in laboratories sitting down or standing in probably not correct positions. We also observed that students from liceo classico (classical studies) had a lower probability of LBP episodes. We can speculate that these students may be accustomed to the study overload and to a more strict discipline typical of the liceo classico. However, it could be interesting to evaluate further questions regarding the school workload and psychological consequences in the context of the alternanza scuola-lavoro project.

We found no connection between playing a music instrument and LBP, but the number of the sample was not big enough to allow us to analyze each instrument separately.

It also seems that there is no relation between the collected anthropometric data and the presence of LBP, while we found an association between gender and low back pain. Girls reported LBP more than boys ( $65 \%$ of females versus $54 \%$ of males). In accordance with other authors, the higher female prevalence in our study is probably due to the different way in which the sexes perceive pain; we excluded various clinical entities that can be responsible for LBP, but we did not ask about the phase of menstrual cycle at the time of the survey.

Through the questionnaire, we investigated the role of extra-school physical activity. We found no connection between playing extra-school physical activity and prevalence of LBP; the number of the sample was not big enough to allow us to analyze each type of physical activity (such as basketball, swimming, dancing, etc.). However, even if the type of physical activity does not seem to be relevant, the intensity of training proves to be associated with the probability of developing LBP. From our results it emerged that practicing physical activity with an intensity of $5 \mathrm{~h} /$ week seems to reduce the probability of developing an episode of LBP. This finding is attractive in terms of prevention, as moderately intense physical activity seems to have a protective function against LBP.

This data is in contrast with what emerged in the paper by Triki et al., even if in their sample only scholastic sport activities were studied and not extra-institute ones (16).

The review by Immaculada, considering 7 studies/17,008 subjects for physical activity and 26 studies/51,510 subjects for sports, found that among schoolchildren, highly intense sport practice was likely to be associated with a higher risk of reporting LBP, as confirmed by our investigation (17).

Pain intensity and medical attention seeking were also investigated through the questionnaire. We found that $50 \%$ of adolescents with LBP consulted a health provider and, of these, $48.6 \%$ carried out instrumental analysis (radiography or magnetic resonance). In the literature, the percentage of adolescents with LBP that had consulted a physician is lower. Some authors reported that consultation rates among adolescents 
with LBP are about $25 \%$, mainly concerning patients with more intense or longerlasting pain $(18,19)$.

In our study sample, $45 \%$ of the examined subjects took drugs to control LBP. A similar percentage of drug use $(42.9 \%$ in males and $47.8 \%$ in females) was observed in a sample of nursing students by Uzunçakmak (20). Using and abusing painkillers is a huge problem. There are various medications to prescribe, depending on the severity of symptoms, the disease ongoing and the exact localization of pain. These include anti-inflammatory drugs, muscle relaxants, corticosteroids and opioids. In our sample, we analyzed different classes of drugs, mostly self-prescribed. People with chronic LBP have higher probability of illicit drug use and, among those, they are more likely to rely on opioid analgesics (21). This however seems to be an aspect of great clinical and socio-economic importance to be explored with further studies. Rehabilitation treatments, such as massage, exercise, and biofeedback, can have an impact on management of drugs themselves. In our sample, $23 \%$ of subjects with LBP underwent rehabilitation treatments and a significant part of the studied subjects gave positive feedback to the possibility of preventing LBP through participation in specific programs. Preventive treatments as postural hygiene, physiotherapy exercises and physical activity can be of help. A meta-analysis defined that the combination of therapeutic physical conditioning and manual therapy is the most effective physical therapy treatments for LBP in children and adolescents (22).

Interestingly, our data reveal that 6 of 10 adolescents from the Veneto region present LBP, showing the considerable impact in health and social performance. Adolescence is a critical period of transition from childhood to adulthood, during which several physical and psychosocial changes take place. This is the reason why we also evaluated the relation between QoL and LBP in our cohort. Although previous studies have documented adolescent LBP impact through questionnaires for children, the strength of our study lies in the use of a standard questionnaire (SF-36) validated also for adults $(23,24)$. In this study, girls reported lower mean values for QoL than boys in all eight scales: physical functioning (PF), physical role limitation (RP), bodily pain (BP), general health (GH), vitality (VT), social functioning (SF), emotional role limitation (RE), and mental health $(\mathrm{MH})$. This could be related to the onset of puberty and its associations to physique changes; in fact, females face great challenges and the onset of menstruation can also cause frequent complaints. The hormonal fluctuations in teenage girls may further contribute to impairment of psychological well-being.

Of note, adolescents experiencing LBP only in the past and those who never experienced LBP had higher and similar QoL scores. The complete resolution of pain seems not to influence their perceived physical and mental health, as if the memory of back pain has been wiped clean after a time of wellbeing.

Observing only the male adolescents, those with LBP had lower QoL, but only in the dimension of vitality.

Considering the female adolescents with LBP, they reported poorer physical and mental QoL measurements than healthy subjects. This finding is consistent with previous researches on the negative impact on well-being of widespread pain and LBP in adolescents (25). The same trend was observed in the study conducted by Paananen et al., where adults with LBP reported higher levels of disability and poorer QoL outcomes (26). The results of our study contrast with those of Pellisé et al. who concluded that LBP has no significant impact in the quality of life of adolescents (27). The difference could be related to the age of the subjects, suggesting the possibility that the impact of LBP may not be evident until late adolescence.

This survey presents some limitations. We did not consider the time spent sitting/ standing during the day, the effects of using school backpacks, which some authors indicate as possible cause of LBP, the adequacy of school and domestic furniture, the menstruation-effect in female subjects 
(28). Moreover, we investigated adolescents only with regard to the presence or not of LBP, without considering the number of LBP episodes. Another limitation is the lack of analysis of unconventional therapies such as chiropractic, osteopathy, acupuncture. These will be additional questions for further surveys in the context of the alternanza scuola-lavoro project.

Further studies are also required to investigate the underlying psychological mechanisms associated with disabling LBP during adolescence. A better knowledge, indeed, could be an effective approach to decreasing the overall social cost caused by LBP.

\section{CONCLUSIONS}

Our study confirmed that LBP is frequent in Italian scholar adolescents from the Veneto region and has a powerful impact on QoL. A better understanding of the association between back pain and health-related quality of life could facilitate the implementation of new intervention approaches to prevention and treatment of back pain. Simple questionnaires can be used to identify patients at a high risk for chronicity considering that the progression to a chronic pattern of pain is linked more to demographic, psychosocial and occupational factors than to the spinal issue itself. Moreover, strategies for reducing the effects of LBP on QoL should be an important focal point for clinicians and health policy makers.

Acknowledgements: The authors would like to thank Emanuela Caputo, Barbara Rossini and Maria Angela Bettanin for their precious work in the alternanza scuola-lavoro project and the secondary schools involved, Marco Polo (Venice), Alle Stimate (Verona) and Duca d'Aosta (Padua), and Hemove Onlus, for their valuable support.

Contributions: PG, IM and LB contribute equally to this manuscript. LB, MC, $\mathrm{SM}$ and LP conceived and designed the research. PG, IM, EF, VL, MC and DG collected data and conducted research. PG, IM, LB, EF, VL and ME analyzed and in- terpreted data. PG, IM and LB wrote the initial manuscript. All authors have reviewed and approved the final manuscript.

Conflict of interests: The authors declare no potential conflict of interests.

Funding: The authors received no specific funding for this work.

\section{REFERENCES}

1. Masiero S, Carraro E, Celia A, et al. Prevalence of nonspecific low back pain in schoolchildren aged between 13 and 15 years. Acta Paediatr. 2008; 97: 212-6.

2. Dagenais S, Caro J, Haldeman S. A systematic review of low back pain cost of illness studies in the United States and internationally. Spine J. 2008; 8: 8-20.

3. Martin BI, Deyo RA, Mirza SK, et al. Expenditures and health status among adults with back and neck problems. JAMA. 2008; 299: 656-64.

4. Jeffries LJ, Milanese SF, Grimmer-Somers KA. Epidemiology of adolescent spinal pain: a systematic overview of the research literature. Spine (Phila Pa 1976). 2007; 32: 2630-7.

5. Michaleff ZA, Kamper SJ, Maher CG, et al. Low back pain in children and adolescents: a systematic review and meta-analysis evaluating the effectiveness of conservative interventions. Eur Spine J. 2014; 23: 2046-58.

6. Kosseim M, Rein R, McShane C. Implementing evidence-based physiotherapy practice for treating children with low back pain: are we there yet? Pediatr Phys Ther. 2008; 20: 179-84.

7. Sato T, Ito T, Hirano T, et al. Low back pain in childhood and adolescence: a cross-sectional study in Niigata City. Eur Spine J. 2008; 17: 1441-7.

8. Jones GT, Macfarlane GJ. Epidemiology of low back pain in children and adolescents. Arch Dis Child. 2005; 90: 312-6.

9. Palermo TM. Impact of recurrent and chronic pain on child and family daily functioning: a critical review of the literature. J Dev Behav Pediatr. 2000; 21: 58-69.

10. Roth-Isigkeit A, Thyen U, Stöven H, et al. Pain among children and adolescents: restrictions in daily living and triggering factors. Pediatrics. 2005; 115: e152-62.

11. Ware JE Jr, Gandek B. Overview of the SF-36 Health Survey and the International Quality of Life Assessment (IQOLA) Project. J Clin Epidemiol. 1998; 51: 903-12.

12. Apolone G, Mosconi P. The Italian SF-36 Health Survey: translation, validation and norming. J Clin Epidemiol. 1998; 51: 1025-36. 
13. Harreby M, Neergaard K, Hesselsøe G, et al. Are radiologic changes in the thoracic and lumbar spine of adolescents risk factors for low back pain in adults? Spine. 1995; 20: 2298-302.

14. Hestbaek L, Leboeuf-Y de C, Kyvik KO, et al. The course of low back pain from adolescence to adulthood. Spine. 2006; 31: 468-72.

15. Noll M, Candotti CT, da Rosa BN, et al. High prevalence of inadequate sitting and sleeping postures: a three-year prospective study of adolescents. Sci Rep. 2017; 7: 14929.

16. Moez T, Abdessalem K, Liwa M, et al. Prevalence and risk factors of low back pain among undergraduate students of a sports and physical education institute in Tunisia. Libyan $\mathrm{J}$ Med. 2015; 10: 26802.

17. Calvo-Muñoz I, Kovacs FM, Roqué M, et al. Risk Factors for Low Back Pain in Childhood and Adolescence. A Systematic Review. Clin J Pain. 2018; 34: 468-84.

18. Watson KD, Papageorgiou AC, Jones GT, et al. Low back pain in schoolchildren: occurrence and characteristics. Pain. 2002; 97: 87-92.

19. Roth-Isigkeit A, Thyen U, Stöven H, et al. Pain among children and adolescents: restrictions in daily living and triggering factors. Pediatrics. 2005; 115: e152-62.

20. Uzunçakmak T, Kılıç M. Pain experience of nursing students and the methods used to cope with pain. Agri. 2017; 29: 117-21.

21. Shmagel A, Krebs E, Ensrud K, et al. Illicit Substance Use in US Adults With Chronic
Low Back Pain. Spine (Phila Pa 1976). 2016; 41: 1372-7.

22. Calvo-Muñoz I, Gómez-Conesa A, SánchezMeca J. Physical therapy treatments for low back pain in children and adolescents: a meta-analysis. BMC Musculoskelet Disord. 2013; 14: 55.

23. O'Sullivan PB, Beales DJ, Smith AJ, et al. Low back pain in 17 year olds has substantial impact and represents an important public health disorder: a cross-sectional study. BMC Publ Health. 2012; 12: 100.

24. Beales DJ, Smith AJ, O'Sullivan PB, et al. Low back pain and comorbidity clusters at 17 years of age: a cross-sectional examination of healthrelated quality of life and specific low back pain impacts. J Adolesc Health. 2012; 50: 509-16.

25. Wedderkopp N, Leboeuf-Yde C, Andersen $\mathrm{LB}$, et al. Back pain reporting pattern in a Danish population-based sample of children and adolescents. Spine. 2001; 26: 1879-83.

26. Paananen M, Taimela S, Auvinen J, et al. Impact of self-reported musculoskeletal pain on health-related quality of life among young adults. Pain Med. 2011; 12: 9-17.

27. Pellisé F, Balagué F, Rajmil L, et al. Prevalence of low back pain and its effect on healthrelated quality of life in adolescents. Arch Pediatr Adolesc Med. 2009; 163: 65-71.

28. Heuscher Z, Gilkey DP, Peel JL, et al. The association of self-reported backpack use and backpack weight with low back pain among college students. J Manipul Physiol Ther. 2010; 33: 432-7. 